\title{
International Unit per Milliliter
}

National Cancer Institute

\section{Source}

National Cancer Institute. International Unit per Milliliter. NCI Thesaurus. Code C67377.

A unit of arbitrary substance concentration (biologic activity concentration) defined as the concentration of one international unit per one milliliter of system volume. 